\title{
Public health impact and cost effectiveness of mass vaccination with live attenuated human rotavirus vaccine (RIX4414) in India: model based analysis
}

\author{
Johnie Rose, doctoral candidate in health services research and policy, ${ }^{1}$ Rachael L Hawthorn, medical \\ student, ${ }^{1}$ Brook Watts, director, inpatient quality improvement, ${ }^{2}$ Mendel E Singer, associate professor, \\ divisions of health services research and policy, public health ${ }^{1}$
}

${ }^{1}$ Case Western Reserve University School of Medicine, Department of Epidemiology and Biostatistics, 10900 Euclid Avenue/WG-57, Cleveland, OH 44106, USA

${ }^{2}$ Louis Stokes Cleveland Veterans Affairs Medical Center, 10701 East Boulevard (111-W), Cleveland, $\mathrm{OH}$ 44106, USA

Correspondence to: J Rose johnie.rose@case.edu

Cite this as: BMJ 2009;339:b3653 doi:10.1136/bmj.b3653

\section{ABSTRACT}

Objectives To examine the public health impact of mass vaccination with live attenuated human rotavirus vaccine (RIX4414) in a birth cohort in India, and to estimate the cost effectiveness and affordability of such a programme. Design Decision analytical Markov model encompassing all direct medical costs. Infection risk and severity depended on age, number of previous infections, and vaccination history; probabilities of use of inpatient and outpatient health services depended on symptom severity.

Data sources Published clinical, epidemiological, and economic data. When possible, parameter estimates were based on data specific for India.

Population Simulated Indian birth cohort followed for five years.

Main outcome measures Decrease in rotavirus gastroenteritis episodes (non-severe and severe), deaths, outpatient visits, and admission to hospital; incremental cost effectiveness ratio of vaccination expressed as net cost in 2007 rupees per life year saved.

Results In the base case, vaccination prevented 28943 (29.7\%) symptomatic episodes, 6981 (38.2\%) severe episodes, 164 deaths (41.0\%), 7178 (33.3\%) outpatient visits, and 812 (34.3\%) admissions to hospital per 100000 children. Vaccination cost 8023 rupees (about $£ 100, € 113, \$ 165)$ per life year saved, less than India's per capita gross domestic product, a common criterion for cost effectiveness. The net programme cost would be equivalent to $11.6 \%$ of the $2006-7$ budget of the Indian Department of Health and Family Welfare. Model results were most sensitive to variations in access to outpatient care for those with severe symptoms. If this parameter was increased to its upper limit, the incremental cost effectiveness ratio for vaccination still fell between one and three times the per capita gross domestic product, meeting the World Health Organization's criterion for "cost effective" interventions. Uncertainty analysis indicated a $94.7 \%$ probability that vaccination would be cost effective according to a criterion of one times per capita gross domestic product per life year saved, and a $97.8 \%$ probability that it would be cost effective according to a criterion of three times per capita gross domestic product. Conclusions Across a wide range of assumptions, mass RIX4414 vaccination in India would probably prevent substantial morbidity and mortality at a cost per life year saved below typical thresholds of cost effectiveness. The opportunity costs of such a programme in this or similar settings, however, should be weighed up carefully.

\section{INTRODUCTION}

Rotavirus is the leading cause of severe gastroenteritis worldwide, infecting virtually every child by the age of 5. Though the incidence of infection is similar around the world and across economic strata, ${ }^{1-7}$ the burden of mortality is borne disproportionately by the world's poorest children. ${ }^{89}$ Some $23 \%$ of the estimated 527000 annual rotavirus deaths occur in India. ${ }^{10}$

The gastroenteritis caused by rotavirus tends to be more severe than that caused by other viral pathogens. The hallmark triad of fever, diarrhoea, and emesis can bring about rapid dehydration. Indeed, severe emesis tends to preclude the use of oral rehydration in the most severe cases. ${ }^{112}$ This fact partially explains the high rotavirus mortality in areas where access to medical care is poor. Given the minimal impact that water and sanitation measures have had on the burden of rotavirus in developing areas, there is wide agreement that effective vaccination represents the most promising prevention strategy against the disease. ${ }^{13} 14$

Since 2004, two new oral rotavirus vaccines have been introduced: a human-bovine reassortant pentavalent rotavirus vaccine and a monovalent live attenuated human rotavirus vaccine. Both vaccines seem to stimulate protection comparable with the partial protection elicited by a single natural infection. ${ }^{15-17} \mathrm{We}$ focused on live attenuated human rotavirus vaccinealso known as RIX4414 - because of the more diverse population in which its efficacy has been tested and the fact that a full course of RIX4414 requires only two doses compared with the three required for the pentavalent vaccine. ${ }^{13}$ 
Despite the promising results generated in efficacy trials of RIX4414 in Europe and the Americas, ${ }^{1516} 18$ the extent to which the vaccine will be effective in poorer Asian nations is unknown. A substantially higher proportion of strains found in these areas is genetically less similar to the vaccine strain in comparison with Western countries, where completed efficacy trials have occurred. ${ }^{1920}$ Two immunogenic outer capsid proteins, VP7 and VP4, are used to classify rotaviruses into $G$ and $P$ serotypes, respectively. These seem to play a key (though not exclusive) role in eliciting host immune responses and have been the focus in developing existing vaccines against rotavirus. To date, epidemiological studies have identified 42 distinct strains defined by unique G-P serotype combinations. ${ }^{21}$ The vaccine is derived from a G1P $[8]$ strain, believed to be the most common worldwide. Globally, just four strains (G1P[8], G3P[8], G4P[8], and G2P[4]) account for $88.5 \%$ of rotavirus diarrhoea. Only $68 \%$ of rotavirus cases in Asia, however, are attributable to these strains. ${ }^{20}$

Studies of both vaccines are ongoing in several developing Asian and African countries; reporting of these data is expected to begin later in $2009 .{ }^{22}$ Based on preliminary results, the World Health Organization has recently recommended inclusion of rotavirus vaccination in these countries' national immunisation programmes, ${ }^{23}$ paving the way for a spate of new rotavirus vaccination programmes in some of the most vulnerable areas beginning as soon as $2010 .{ }^{22}$

Accompanying concerns about the vaccine's real world effectiveness in developing settings is a daunting set of economic challenges. The current generation of rotavirus vaccines costs substantially more than traditional childhood vaccines given in these countries. ${ }^{22}$ Even with manufacturers' commitments to tiered pricing, ${ }^{24}$ achieving universal vaccination in the world's most affected areas will require substantial help from the international community. ${ }^{25} \mathrm{WHO}$ has emphasised the need for thorough examination of economic issues in the introduction of a rotavirus vaccination programme in any developing country. ${ }^{26}$

Past models of rotavirus vaccination in developing Asian countries ${ }^{27-29}$ (none have been set in India) have not captured much of the complexity of rotavirus epidemiology. The model we describe here differs fundamentally in that it simulates, in a temporally explicit fashion, the sequence of events from infection to development of symptoms, use of health services, disease outcome, recovery, and reinfection for a birth cohort of heterogeneous individuals. One recent analysis used a similarly sophisticated epidemiological model to examine the impact of vaccination in Vietnam, a country with substantially lower rates of mortality from rotavirus and markedly different distributions of rotavirus strain relative to India. ${ }^{30}$ In comparison with that model, we use methods allowing us to better predict shifts in the mix of inpatient and outpatient care that might result from decreased severity of symptoms among vaccinated children who become infected.
We estimated the public health impact of mass vaccination with RIX4414 for a birth cohort in India and examined the incremental cost effectiveness and affordability of such a programme.

\section{METHODS}

\section{Model overview}

We developed an individual based Markov model, which we analysed using Monte Carlo microsimulation methods with TreeAge Pro 2008 software (Williamstown, MA). The base case evaluates only direct medical costs, including those incurred by patients' families or by any public sector entity contributing toward the cost of care. In a secondary analysis from the societal perspective, we also included direct nonmedical costs such as transportation expenses for patients' families and indirect costs such as foregone wages of parents caring for sick children. The model's time horizon consisted of 60 one month cycles. We assumed that administration of the vaccine would be piggybacked on the existing WHO expanded programme on immunisation and given concomitantly with other routine vaccinations, including oral polio vaccine. ${ }^{31-33}$

Possible states of individuals in the model were well, rotavirus diarrhoea, and dead (fig 1). At the end of each cycle spent in the well state, individuals faced a risk of rotavirus infection that could be either asymptomatic or symptomatic. Those acquiring asymptomatic infection began the next stage of the model in the well state, while those acquiring symptomatic infection began the next stage in the rotavirus diarrhoea state. In this diarrhoea state, individuals experienced either severe (Vesikari score ${ }^{34} \geq 11$ ) or non-severe (score $<11$ ) symptoms, the probabilities of which were based on their history of previous infections and vaccination. Symptom severity influenced the likelihood that an individual would receive inpatient, outpatient, or home treatment. At the end of a cycle spent in the diarrhoea state, survivors could either transition to the well state or develop a new symptomatic rotavirus infection, reentering the diarrhoea state for another cycle.

Each possible chance event in the model was associated with an evidence based probability and the exact sequence and timing of events experienced by a given individual were the results of random number draws occurring at each juncture of the model. We aggregated the experience of 200000 simulated individuals to predict the expected number of rotavirus infections (up to three per individual); their severity; the number of admissions to hospital, clinic visits, and home treatments for rotavirus gastroenteritis; the total cost of rotavirus related use; and the number of rotavirus related deaths under two different strategies: universal vaccination with RIX4414 at the recommended ages of 2 and 4 months ${ }^{35}$ versus no vaccination (the status quo).

\section{Incidence, morbidity, and mortality}

Rates of rotavirus infection (but not outcomes of infection) are similar worldwide. ${ }^{836}$ Accordingly, we chose to base parameters related to infection risk on a 


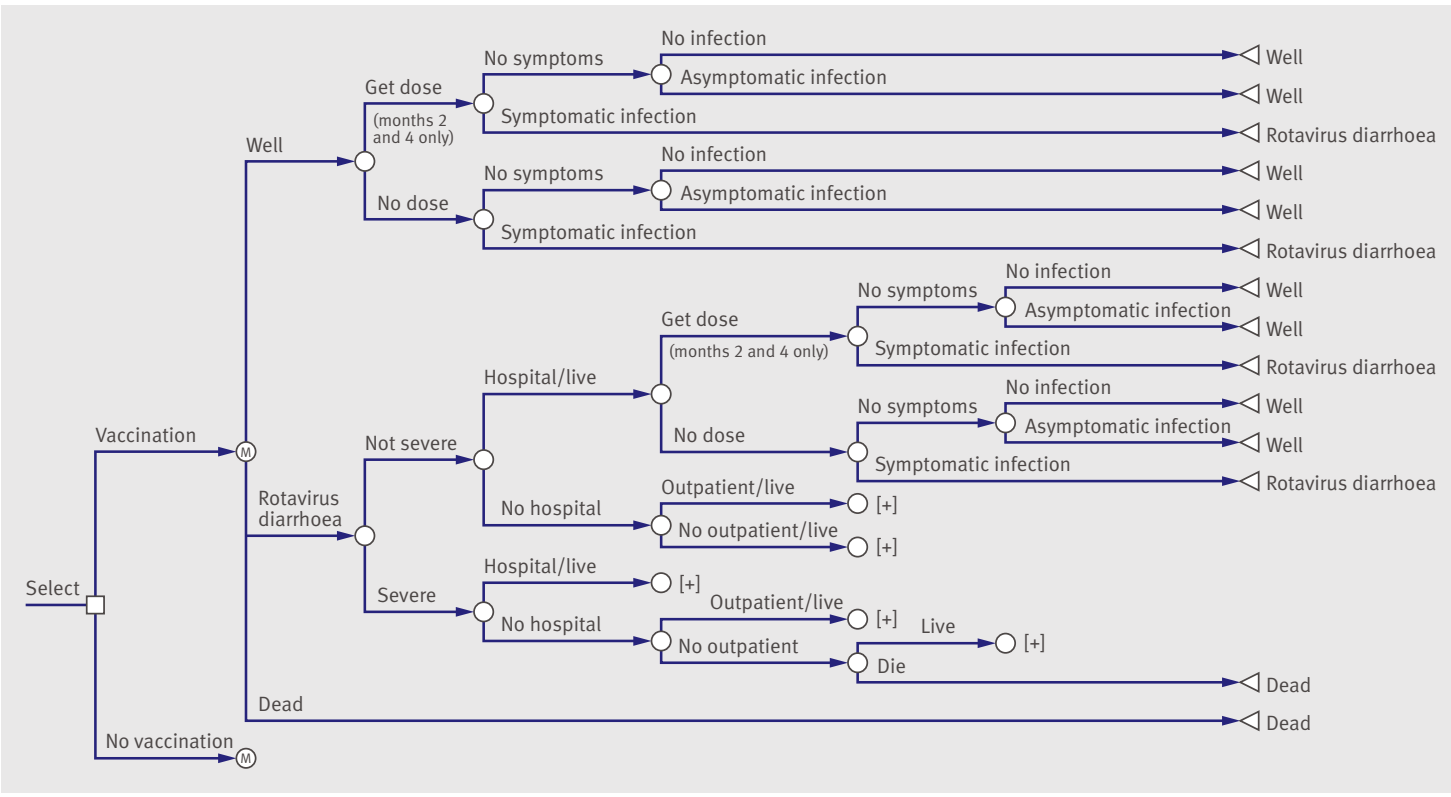

Fig 1| Schematic of Markov model. Each individual begins life in the well state and thereafter resides in either the well, symptomatic, or dead state during each one month cycle for a total of 60 cycles. Individuals can receive doses of live attenuated human rotavirus vaccine at months two and four only. At the end of each cycle, each individual's risk for rotavirus infection is determined by number of vaccine doses received, time since receiving most recent dose, and number of previous rotavirus infections. If infected, individuals might develop symptoms in which case they will begin the next cycle in symptomatic state. In symptomatic state, gastroenteritis can be non-severe (Vesikari score <11) or severe (Vesikari score $\geq 11$ ). Symptom severity dictates probability that each individual will receive hospital care, outpatient care, or no formal treatment. Those with severe disease who receive no formal treatment are at risk for death. Each month, there is an age dependent background risk of death from non-rotavirus causes (not shown). $M$ in circle represents Markov node; branches emanating from a Markov node represent possible states of being. Open circle represents chance node; branches emanating to right represent possible outcomes of probabilistic process. Left pointing triangle designates terminal node; here, the state in which next cycle should begin is given. [+] signifies that portion of tree has been collapsed because it replicates portion already shown. "Get dose" signifies contingency that individual receives dose of vaccine, "no dose" signifies that they do not

rigorous prospective study of rotavirus incidence in a cohort of 200 Mexican infants followed from birth to 24 months of age. ${ }^{2}$ Velazquez and colleagues ${ }^{2}$ closely monitored children for rotavirus infection with serial stool assays and serum immunoassays (a similar study done in west Africa did not use serum immunoassays and thus probably failed to capture a non-trivial number of infections ${ }^{37}$ ). Investigators recorded the time to first and subsequent infections and the severity of each infection (including asymptomatic) for each individual during follow-up. Based on the reported cumulative incidence of the nth infection at 6,12 , and 24 month intervals (table 1), we calculated one month hazard rates and converted these to one month transition probabilities corresponding to the appropriate age interval and number of previous infections. Hazard rates for the 12 to 24 month interval formed the basis for transition probability estimates for the nth infection after the 24 th cycle. Figure 2 shows the cumulative incidence of first to the third rotavirus infection produced by our model for children who were not vaccinated. Data from the same cohort also served as the basis for estimates of probabilities that those infected would experience no symptoms, non-severe symptoms, or severe symptoms with first to the third infections. Severity (or lack) of symptoms did not influence the degree of natural protection conferred against subsequent rotavirus re-infection. ${ }^{17}$ We varied parameters related to disease burden extensively in sensitivity analyses.

Consistent with recent experience in India, ${ }^{1138}$ individuals receiving formal medical attention (hospital, clinic, or emergency department care) faced no risk of death from rotavirus, irrespective of the severity of gastroenteritis. We determined the model parameter representing probability of death for those with severe rotavirus gastroenteritis who did not receive formal medical attention by using a simple calibration technique. We varied the parameter systematically until the model produced a five year risk of rotavirus mortality in the no vaccination group that matched observed rotavirus mortality in India (one in 250 children $^{14}$ ). We did not explicitly incorporate any additional survival benefit from home oral rehydration as the effect of such treatment at prevailing levels of access and effectiveness should already be implicitly reflected in the Indian rotavirus mortality figure to which we calibrated. Within each cycle all individuals also faced an age dependent probability of death from non-rotavirus causes based on published Indian life tables. ${ }^{39}$

\section{Vaccine characteristics}

We assumed that coverage rates for doses one and two of the vaccine would match rates for doses one and 
Table 1|Disease related parameters. Estimated values, ranges used in sensitivity analysis, and distribution types assumed for uncertainty analysis. Upper and lower limits of ranges correspond to $95 \%$ confidence intervals. Standard errors used in creating probability distributions for each parameter were estimated as quarter of range between confidence limits ${ }^{56} 57$

\begin{tabular}{|c|c|c|c|c|}
\hline Parameter & Value & Range & Source/comments & $\begin{array}{l}\text { Distribution used } \\
\text { in uncertainty analysis }\end{array}$ \\
\hline \multicolumn{5}{|c|}{ Cumulative incidence of nth infection by 6,12 , and 24 months*: } \\
\hline First infection & $0.34 \dagger, 0.67,0.96$ & $\begin{array}{l}\text { Calculated transition } \\
\text { probabilities varied }+/-50 \%\end{array}$ & Velazquez et $\mathrm{al}^{2}$ & Normal \\
\hline Second infection & $0.04,0.30,0.69$ & $\begin{array}{l}\text { Calculated transition } \\
\text { probabilities varied }+/-50 \%\end{array}$ & Velazquez et $\mathrm{al}^{2}$ & Normal \\
\hline Third infection & $0.00,0.07,0.42$ & $\begin{array}{l}\text { Calculated transition } \\
\text { probabilities varied }+/-50 \%\end{array}$ & Velazquez et $\mathrm{al}^{2}$ & Normal \\
\hline $\begin{array}{l}\text { Probability that } 1 \text { st, } 2 \text { nd, and } 3 \text { rd infections, } \\
\text { respectively, will cause symptoms }\end{array}$ & $0.47,0.32,0.25$ & $+/-50 \%$ & Velazquez et $\mathrm{al}^{2}$ & Normal \\
\hline $\begin{array}{l}\text { Probability that symptoms, if present, will be severef } \\
\text { (1st, 2nd, 3rd infections) }\end{array}$ & $0.28,0.19,0.00$ & $+/-50 \%$ & Velazquez et al ${ }^{2}$ & Normal \\
\hline $\begin{array}{l}\text { Probability of dying from severe rotavirus disease } \\
\text { without formal medical attention }\end{array}$ & 0.068 & $0.034-0.136$ & $\begin{array}{l}\text { Calibrated to yield known five year } \\
\text { rotavirus mortality of } 1 / 250^{14} \text { in "no } \\
\text { vaccination" group }\end{array}$ & Beta \\
\hline
\end{tabular}

Prevalence of rotavirus strains with:

\begin{tabular}{|c|c|c|c|c|}
\hline $\mathrm{G}$ and $\mathrm{P}$ proteins in common with RIX4414 & 0.275 & - & \multirow{3}{*}{$\begin{array}{l}\text { Composite of three recent } \\
\text { epidemiological studies from } \\
{\text { Delhi, }{ }^{42} \text { Kolkata, }{ }^{43} \text { Vellore }}^{38}\end{array}$} & - \\
\hline Either G or P in common with RIX4414 & 0.238 & - & & - \\
\hline Neither G nor P in common with RIX4414 & 0.487 & - & & - \\
\hline
\end{tabular}

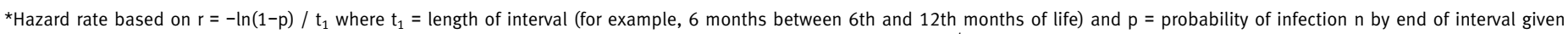
being at risk for infection $n$ at beginning of interval, transition probability calculated from hazard rate as $p=1-e^{-r t}{ }_{2}$ where $t_{2}=c y c l e$ length (one month for present model).

tBased on observation that infections by pathogenic rotavirus strains in first few months of life are rare, ${ }^{11}$ we set probability of infection before 2 months of age to 0.

$\ddagger$ Severe infections are defined as those with Vesikari score $\geq 11 .^{34}$

three of the diphtheria-tetanus-pertussis vaccine in India (given on the same schedule as RIX4414) (table 2 ). ${ }^{2231}$ Using a previously validated technique, ${ }^{40}$ we estimated setting specific efficacy based on serotype specific efficacy data ${ }^{1641}$ and combined prevalence figures from northern, ${ }^{42}$ eastern, ${ }^{43}$ and southern ${ }^{38}$ India. Where the figures for serotype specific efficacy from a large trial that took place almost entirely in Latin America ${ }^{16}$ were significant, we used these. In the case of $\mathrm{G}_{2} \mathrm{P}^{4}$ efficacy, where results from this single trial did not reach significance, we relied on data from a recently published meta-analysis that also included data from high income countries of Europe and Singapore. ${ }^{41}$ We projected that efficacy against severe disease would be 0.804 in India (compared with 0.847 from the Latin American trial ${ }^{16}$ and 0.958 from a trial in six European countries ${ }^{18}$ ).

In the absence of analogous serotype specific data from trials needed to estimate efficacy against any rotavirus symptoms, we estimated this value by adjusting our projected efficacy against severe disease by the ratio of overall (that is, all strains) efficacy against any symptomatic infection to overall efficacy against severe infection from a recent phase III trial. ${ }^{18} \mathrm{Simi}-$ larly, to estimate the vaccine's efficacy against asymptomatic infection in India, we adjusted the projected vaccine efficacy against severe infection by the ratio of efficacy against asymptomatic to severe infection reportedly conferred by the first naturally acquired rotavirus infection. ${ }^{2}$

We considered the efficacy of a single dose of RIX4414 to be $37.5 \%$ lower than that of a full two dose course. $^{44}$ The annual rate of waning of efficacy was based on the differential between the first and second season efficacy in a large Latin American trial ${ }^{45}$ and converted into monthly rates for our model.

We assumed no risk of serious adverse events for those receiving the vaccine. An earlier tetravalent rhesus recombinant rotavirus vaccine, Rotashield, was removed from the market in 1999 after it was linked to an increase in intussusception events among recipients in the United States. ${ }^{14}$ The combined clinical trial and post-marketing data pertaining to RIX4414 suggest no increased rates of adverse events, including intussusception. $^{46}$

\section{Probabilities related to use of health services}

Probabilities that symptomatic individuals would receive inpatient care depended on the severity of symptoms and were derived with Bayes's formula with the following inputs: proportion of rotavirus inpatients in India who have severe/non-severe

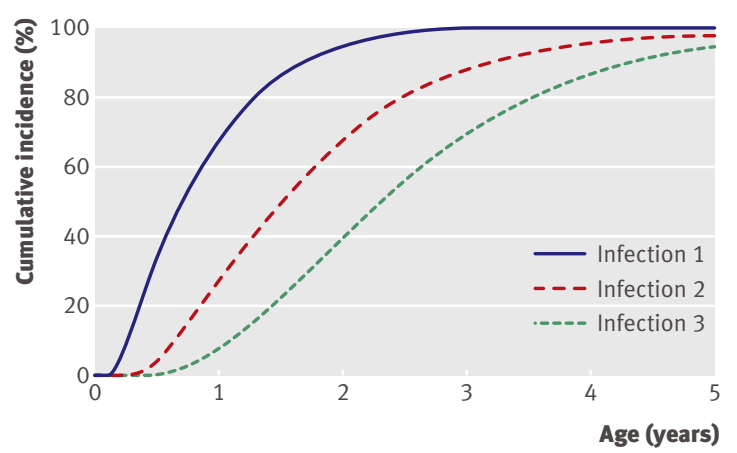

Fig 2 | Model projections for cumulative incidence of first, second, and third rotavirus infections during first five years of life in children receiving no vaccination 
Table 2 |Vaccine related parameters. Estimated values, ranges used in sensitivity analysis, and distribution types assumed for uncertainty analysis. Upper and lower limits of ranges correspond to estimates of $95 \%$ confidence intervals. Standard errors used in creating probability distributions for each parameter were estimated as quarter of range between confidence limits ${ }^{56} 57$

\begin{tabular}{|c|c|c|c|}
\hline Parameter & Value (range) & Source/comments & $\begin{array}{l}\text { Distribution used } \\
\text { in uncertainty analysis }\end{array}$ \\
\hline Coverage for dose 1 (age 2 months) & $0.81(0.71$ to 0.91$)$ & Based on DPT-1 coverage 31 & $\beta$ \\
\hline Coverage for dose 2 (age 4 months) & 0.77 (0.67 to 0.87$)$ & Based on DPT-3 coverage ${ }^{31}$ & $\beta$ \\
\hline \multicolumn{4}{|l|}{ Efficacy against severe infection caused by rotavirus strains with: } \\
\hline $\mathrm{G}$ and P proteins in common with RIX4414 & $0.908\left(0.705\right.$ to $\left.0.982^{\star}\right)$ & Ruiz-Palacios et al ${ }^{16}$ & $\beta$ \\
\hline Either $\mathrm{G}$ or $\mathrm{P}$ in common with RIX4414 & $0.869\left(0.628\right.$ to $\left.0.966^{\star}\right)$ & Ruiz-Palacios et al ${ }^{16}$ & $\beta$ \\
\hline Neither G nor P in common with RIX4414 & $0.714\left(0.201\right.$ to $\left.0.911^{\star}\right)$ & De Vos et al $^{41}$ & $\beta$ \\
\hline $\begin{array}{l}\text { Ratio of efficacy against any symptomatic rotavirus infection } \\
\text { to efficacy against severe infection }\end{array}$ & $0.873(0.773$ to 0.973$)$ & Vesikari et al $^{18}$ & $\beta$ \\
\hline $\begin{array}{l}\text { Ratio of efficacy against asymptomatic infection to efficacy } \\
\text { against severe infection }\end{array}$ & $0.437(0.337$ to 0.537$)$ & Velazquez et $\mathrm{al}^{2}$ & $\beta$ \\
\hline Proportion of full efficacy conferred by single dose & $0.625(0.425$ to 0.825$)$ & Lopez et $\mathrm{al}^{44}$ & $\beta$ \\
\hline Assumed annual rate of waning in vaccine efficacy & $0.049(0.0$ to 0.10$)$ & $\begin{array}{l}\text { Based on decline in efficacy between } 1 \text { st } \\
\text { and } 2 \text { nd seasons in two year trial in Latin America }{ }^{45}\end{array}$ & $\beta$ \\
\hline
\end{tabular}

*Ranges based on actual $95 \%$ confidence intervals from trial data.

symptoms ${ }^{38}$ five year cumulative incidence of severe/ non-severe rotavirus infection (taken directly from the output of our model for the no vaccination strategy), and five year cumulative probability of admission to hospital for rotavirus. We estimated this last input at $1.55 \%$ by varying it until the model projected the same probability of admission given any rotavirus symptoms that Parashar et al estimated for low income countries. ${ }^{8}$ We estimated severity dependent probabilities of use of outpatient services in the same manner. Based on mean severity scores of Indian children presenting with rotavirus infection in inpatient versus outpatient settings, ${ }^{47}$ we assumed that the proportion of outpatients whose symptoms were severe would be half that of inpatients.

Using these inputs, we estimated the probability of admission given severe infection as $9.7 \%$, the probability of admission given non-severe infection as $0.72 \%$, the probability of outpatient treatment given severe infection as $57.5 \%$, and the probability of outpatient treatment given non-severe infection as 14.1\% (table 3). Those not receiving any formal medical treatment were considered to have been treated at home by the family with a probability of oral rehydration solution use corresponding to known levels of oral rehydration therapy access in India. ${ }^{48}$

\section{Costs}

We do not know the precise cost per dose that would be paid as part of a universal RIX4414 vaccination programme in India. The manufacturer (GlaxoSmithKline) has pledged to make the vaccine available at greatly reduced prices to public sector programmes in lower income countries. ${ }^{24}$ The manufacturer recently sold millions of doses to the government of Brazil at a cost of $\$ 7(£ 4, € 4.8)$ per dose. ${ }^{24}$ We used this figure (converted to 2007 rupees) as a baseline estimate for the vaccine's cost and varied it substantially in sensitivity analysis (table 3). We also do not know the degree of increase in administration costs that would be incurred by adding RIX4414 to the existing vacci nation schedule. Consistent with other investigators, ${ }^{2829}$ we applied an administration cost equivalent to $\$ 0.50$ a dose. We also varied this value over a wide range, given doubts about the adequacy of many poorer countries' cold chain infrastructure to accommodate the added volume of a bulky new oral vaccine. ${ }^{25}$ We assumed a standard $10 \%$ rate of vaccine wastage. ${ }^{272849}$

We were fortunate to have recent data on direct medical, direct non-medical, and indirect costs from a study of the economic burden of rotavirus treatment in Vellore, India. ${ }^{47}$ Based on WHO guidelines for gathering cost data on treatment of diarrhoea, ${ }^{50}$ the investigators followed hospital, clinic, and emergency department patients (we combined the latter two categories into one "outpatient" category) prospectively in three facilities serving markedly different populations of patients. We weighted the costs reported for each treatment setting (inpatient or outpatient) at each facility by the reported number of encounters in each setting and facility to estimate average costs for inpatient and outpatient treatment.

\section{Cost effectiveness analysis}

We determined the incremental cost effectiveness ratio for moving from a strategy of no vaccination to a strategy of universal two dose vaccination with RIX4414. For the base case analysis, this ratio was expressed in 2007 Indian rupees per life year saved and was calculated as the difference in mean cost under the vaccination strategy compared with that under the no vaccination strategy divided by the difference in years of life lost between the two strategies. Costs and benefits were discounted at a standard annual rate of $3 \%$, consistent with previous analyses. ${ }^{28294951}$ In a secondary analysis, we calculated the incremental cost effectiveness in terms of discounted rupees per disability adjusted life year (DALY) averted (by using standard age weighting and discounting ${ }^{52}$ ). Based on the 
Table $3 \mid$ Utilisation and cost parameters. Estimated values, ranges used in sensitivity analysis, and distribution types assumed for uncertainty analysis. Upper and lower limits of ranges correspond to estimates of $95 \%$ confidence intervals. Standard errors used in creating probability distributions for each parameter were estimated as quarter of range between confidence limits ${ }^{56} 57$

\begin{tabular}{|c|c|c|c|}
\hline Parameter & Value (range) & Source/comments & $\begin{array}{l}\text { Distribution used } \\
\text { in uncertainty analysis }\end{array}$ \\
\hline \multicolumn{4}{|l|}{ Probabilities related to use of health services } \\
\hline \multicolumn{4}{|l|}{ Probability of admission to hospital given: } \\
\hline Non-severe infection & $0.00721(0.00361$ to 0.0108$)$ & Calculated based on ${ }^{83 *}$ & $\beta$ \\
\hline Severe infection & $0.0973(0.0487$ to 0.146$)$ & Calculated based on ${ }^{88 *}$ & $\beta$ \\
\hline \multicolumn{4}{|l|}{ Probability of outpatient treatment given: } \\
\hline Non-severe infection & $0.141(0.0705$ to 0.212$)$ & Calculated based on ${ }^{83 *}$ & $\beta$ \\
\hline Severe infection & $0.575(0.288$ to 0.863$)$ & Calculated based on ${ }^{88 *}$ & $\beta$ \\
\hline $\begin{array}{l}\text { Probability of access to oral rehydration solution at } \\
\text { home }\end{array}$ & $0.30(0.0$ to 1.0$)$ & Jain et $\mathrm{al}^{48}$ & $\beta$ \\
\hline \multicolumn{4}{|l|}{ Costs (in 2007 rupees) $\dagger$} \\
\hline Cost of one dose of RIX 4414 & $285.2(142.6$ to 570.4$)$ & $\begin{array}{l}\text { Based on price paid by Brazilian } \\
\text { government }{ }^{25}\end{array}$ & Triangular \\
\hline Cost of administering vaccine (per dose) & 20.4 (10.2 to 81.6$)$ & Podewils et $a{ }^{28}{ }^{28}$ Isakbaeva et al ${ }^{29}$ & Triangular \\
\hline \multicolumn{4}{|l|}{ Hospital treatment of rotavirus infection: } \\
\hline \multicolumn{4}{|l|}{ Direct medical: } \\
\hline Paid by patient's family & 2444.3 (1833.2 to 3055.4$)$ & Mendelsohn et $\mathrm{al}^{47}$ & Normal \\
\hline Subsidised by government & 189.4 (142.1 to 236.8$)$ & Mendelsohn et $\mathrm{al}^{47}$ & Normal \\
\hline Direct non-medical & 39.9 (29.9 to 49.9) & Mendelsohn et $\mathrm{al}^{47}$ & Normal \\
\hline Indirect & 0 & Mendelsohn et $\mathrm{al}^{47}$ & NA \\
\hline \multicolumn{4}{|l|}{ Outpatient treatment of rotavirus infection: } \\
\hline \multicolumn{4}{|l|}{ Direct medical: } \\
\hline Paid by patient's family & $156.2(117.2$ to 195.3$)$ & Mendelsohn et $\mathrm{al}^{47}$ & Normal \\
\hline Subsidised by government & $52.1(39.1$ to 65.1$)$ & Mendelsohn et $\mathrm{al}^{47}$ & Normal \\
\hline Direct non-medical & $23.6(17.7$ to 29.5$)$ & Mendelsohn et $\mathrm{al}^{47}$ & Normal \\
\hline Indirect & 1.8 (1.4 to 2.3$)$ & Mendelsohn et $\mathrm{al}^{47}$ & Normal \\
\hline Oral rehydration solution (per course) & $15.4(11.3$ to 18.8$)$ & Patel et $\mathrm{al}^{80}$ & Normal \\
\hline Discount rates & & & - \\
\hline For costs & $3 \%(0 \%$ to $3 \%)$ & - & - \\
\hline For benefits & $3 \%(0 \%$ to $3 \%)$ & - & - \\
\hline
\end{tabular}

age specific disability weight for diarrhoea reported in the Global Burden of Disease Study ${ }^{53}$ and a typical duration of symptoms of one week, ${ }^{19}$ we used a disability weight of 0.0023 per symptomatic episode.

Often, a threshold of one $\mathrm{e}^{284951}$ to two ${ }^{54}$ times a country's per capita gross domestic product is used as a criterion to gauge whether the incremental cost of an intervention per life year saved or per DALY averted can be considered sufficiently cost effective. WHO describes interventions costing less than a country's per capita gross domestic product per DALY averted as "very cost effective" and those costing between one and three times per capita gross domestic product as "cost effective." 55 Though our main cost effectiveness measure was cost per life year saved - not per DALY averted-we chose a threshold of one times per capita gross domestic product. This approach is slightly more conservative than basing the threshold on DALYs averted as life years saved do not capture the nonfinancial benefits of reducing symptoms in non-fatal cases. $^{51}$
Sensitivity and uncertainty analyses

To assess the overall robustness of our model and to identify influential parameters for which better empirical data are needed, we performed one way sensitivity analyses by individually varying each input parameter across the ranges shown in the tables.

To help us gauge the overall impact of parameter uncertainty, we also performed a type of uncertainty analysis, known as two dimensional probabilistic sensitivity analysis, by creating probability distributions for nearly all parameters in the model. For estimates of administration costs and for cost of the vaccine itself, we applied triangular distributions with limits of 50\% and $300 \%$, and $50 \%$ and $200 \%$, respectively. For all other costs, we used normal distributions with $95 \%$ confidence intervals equal to plus or minus $25 \%$ of the mean. We inserted three separate constants (each with a base value of 1.0) in our model, which, when varied, affected the calculated transition probabilities for $n$th infection, the probabilities that infection $n$ would cause symptoms, and the probabilities that symptoms of infection n, if present, would be severe. 
Table 4 Expected clinical events and use of health services related to rotavirus infection in birth cohort of 100000 Indian infants followed for five years under strategies of no vaccination and vaccination with RIX4414

\begin{tabular}{lccc} 
Clinical events per $\mathbf{1 0 0 ~} 000$ children & No vaccination & Vaccination & Change (\%) \\
\hline Any infection & & & \\
\hline Asymptomatic infections & 278672 & 253657 & $-25015(-9.0)$ \\
\hline Symptomatic infections & 181164 & 185092 & $3928(2.2)$ \\
\hline Severe infections & 97508 & 68565 & $-28943(-29.7)$ \\
\hline Deaths & 18260 & 11279 & $-6981(-38.2)$ \\
\hline Use of health services per 100 000 children & 398 & 235 & $-163(-41.0)$ \\
\hline Home treatment with oral rehydration solution & 73221 & 52191 & $-21030(-28.7)$ \\
\hline Outpatient visits & 21582 & 14405 & $-7177(-33.3)$ \\
\hline Admissions to hospital & 2367 & 1555 & $-812(-34.3)$ \\
\hline
\end{tabular}

These three constants were varied over a normal distribution with $95 \%$ confidence limits of 0.5 and 1.5 . For all other proportions and probabilities, we used $\beta$ distributions with $\alpha$ and $\beta$ parameters estimated from mean and standard error. We estimated standard errors based on the approximation that lower and upper limits used in one way sensitivity analysis represented $95 \%$ confidence limits, with ranges equal to approximately four times the standard error. ${ }^{5657}$ One thousand probabilistically sampled parameter sets (a typical number in decision analyse ${ }^{58-61}$ ) were each used to simulate a cohort of 100000 individuals. We then calculated the proportion of these 1000 samplings that would have produced results considered cost effective.

\section{RESULTS}

Base case

The model predicted that, without vaccination, essentially all children would have had a first infection by 60 months of age (consistent with conventional wisdom $^{81362}$ ), 98.6\% would have had a second infection, and $94.4 \%$ would have had a third infection (fig 2). Table 4 shows the projected numbers of clinical events and use of health services per 100000 children followed for five years under both strategies. Based on an actual Indian birth cohort size of about 25 million a year, ${ }^{63}$ each year vaccination would be expected to prevent 1745000 severe episodes of gastroenteritis, 1794500 outpatient visits, 203000 admissions to hospital, and 41000 deaths among children younger than 5 years.

The additional direct medical cost incurred by moving from no vaccination to the vaccination strategy (net

Table $\mathbf{5}$ | Base case cost effectiveness results: strategy of no vaccination compared with strategy of vaccination with two doses of RIX4414

\begin{tabular}{lccccc} 
& $\begin{array}{c}\text { Mean cost } \\
\text { (2007 rupees) }\end{array}$ & Marginal cost & $\begin{array}{c}\text { Mean years } \\
\text { of life lost }\end{array}$ & $\begin{array}{c}\text { Life years } \\
\text { saved (LYS) }\end{array}$ & $\begin{array}{c}\text { ICER* } \\
\text { (rupees/LYS) }\end{array}$ \\
No vaccination & 106.5 & - & 2.06627 & - & - \\
\hline Vaccination & 538.9 & 432.4 & 2.01237 & 0.05390 & 8023 \\
\hline
\end{tabular}

*Incremental cost effectiveness ratio (ICER) calculated as marginal cost in 2007 rupees divided by life years saved. of any savings from reduced expenditures for treatment) would be 432.4 rupees (about $£ 5, € 6, \$ 9$ ) per person. On average, vaccination would be expected to save 0.05390 life years per person, yielding an incremental cost effectiveness ratio of 8023 rupees (or about $£ 100, € 113, \$ 164)$ per life years saved (table 5). The intervention would thus satisfy our cost effectiveness criterion of less than India's per capita gross domestic product (37 907 rupees in $2007^{64}$ ) per life year saved. Taking the broader societal perspective, the incremental cost effectiveness ratio was 7984 rupees per life year saved. With DALYs averted as an alternative measure of effectiveness, the ratio was 6552 rupees per DALY averted.

\section{Sensitivity analysis}

In a sensitivity analysis, increasing the coverage level for the first and second doses of the vaccine by 10 percentage points increased the reduction in mortality due to vaccination from $41.1 \%$ to $47.6 \%$, saving an additional 6500 lives annually population-wide. We also examined the impact of vaccination under a scenario of low efficacy in which each strain specific efficacy figure shown in table 2 was reduced by 15 percentage points. Even at this substantially reduced efficacy, vaccination could still be expected to save 26750 lives in one year with an incremental cost effectiveness of 11647 rupees per life year saved.

Figure 3 shows the individual parameters which, when varied across their full ranges, most affected the incremental cost effectiveness ratio from baseline. Increasing the probability that children with severe symptoms would present for outpatient treatment by $50 \%$ increased the ratio to 51637 rupees per life year saved, an effect driven mainly by a $92 \%$ reduction in mortality that was independent of vaccination status. This was the only individual parameter capable of increasing the incremental cost effectiveness ratio above per capita gross domestic product. There is marked asymmetry of results for parameters which, when varied, would affect individuals in both the vaccination and no vaccination groups. In each of these cases, changes that lessen the morbidity or mortality of disease reduce the cost effectiveness of vaccination (resulting in higher incremental cost effectiveness ratios). When disease is less serious, the potential marginal health benefit of vaccination (the denominator of the incremental cost effectiveness ratio) becomes smaller. Meanwhile, marginal cost in the numerator tends to increase with less serious disease as savings on treatment costs due to vaccination become more modest.

We explored a scenario in which the overall infection rate, probability of symptoms given infection, and probability that any symptoms would be severe were simultaneously increased by $50 \%$. In this scenario of higher disease burden, absolute mortality reduction per 100000 due to vaccination rose from 164 to 310 lives, while the incremental cost effectiveness fell to 5007 rupees per life year saved.

Alternative discount rates of $0 \%$ for costs and $0 \%$ for health benefits yielded an incremental cost 


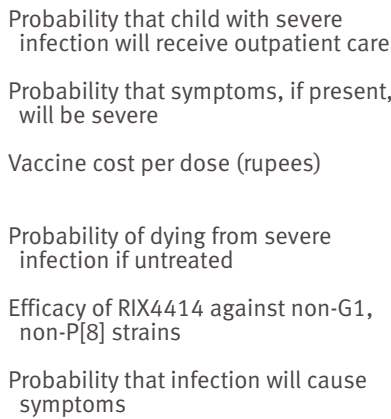

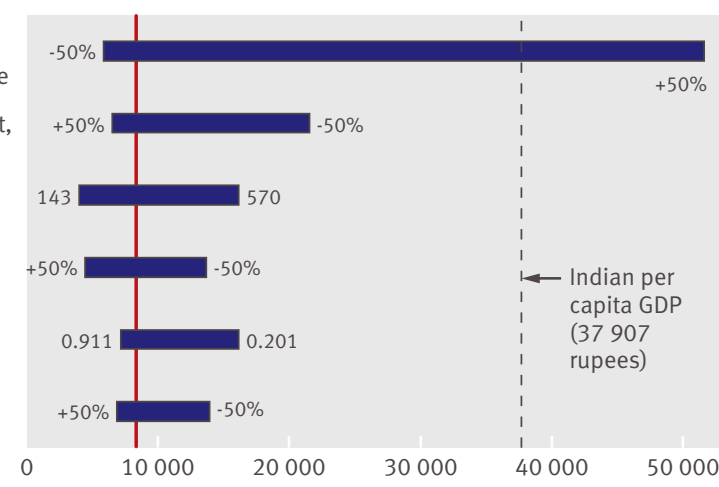

ICER (rupees/LYS)
Fig 3 | Individual parameters with greatest influence on incremental cost effectiveness ratio, expressed in rupees per life year saved (LYS), in univariate sensitivity analysis. Solid vertical line represents base case incremental cost effectiveness ratio of 8023 rupees per life year saved to care greatly reduced baseline rotavirus mortality, diminishing the potential mortality benefit of vaccination. Uncertainty analysis suggested that, given the combined extent of uncertainty in all parameter estimates, vaccination would satisfy a conservative one times per capita gross domestic product criterion for cost effectiveness with $94.7 \%$ probability. Furthermore, it would satisfy WHO's three times the per capita gross domestic product criterion with $97.8 \%$ probability.

\section{Strengths of study}

This study features several methodological strengths. The model simulates clinical events and use of health services in a temporally explicit fashion that incorporates the changing effects of each individual's age, infection history, and vaccination history on infection risk and response to infection. Vaccine efficacy is adjusted to account for distributions of strains specific to India. Monthly probabilities of infection are based on hazard rates calculated from a meticulously executed birth cohort study, which captured even asymptomatic infections. Use of such complete epidemiological data in a model of rotavirus infection is important given the role of asymptomatic infections in reducing risk and severity of future infections. In addition, the study benefited from the availability of recent cost data. ${ }^{47}$

We found no previously published analyses that examined the impact of rotavirus vaccination specifically in India. A study by Podewils et al published in 2005 examined the cost effectiveness of vaccination for low income Asian countries. ${ }^{28}$ We consider, though, that these investigators might have substantially overestimated the incidence of admission to hospital, leading to significant overestimation of cost savings from vaccination. They applied a one year cumulative incidence of admission for rotavirus among children aged 0-60 months ${ }^{11}$ to a hypothetical cohort of infants followed for five years by simply multiplying the incidence by five. If the closed group of children aged 0-60 months in the source study had been followed for subsequent years, however, much lower rates of

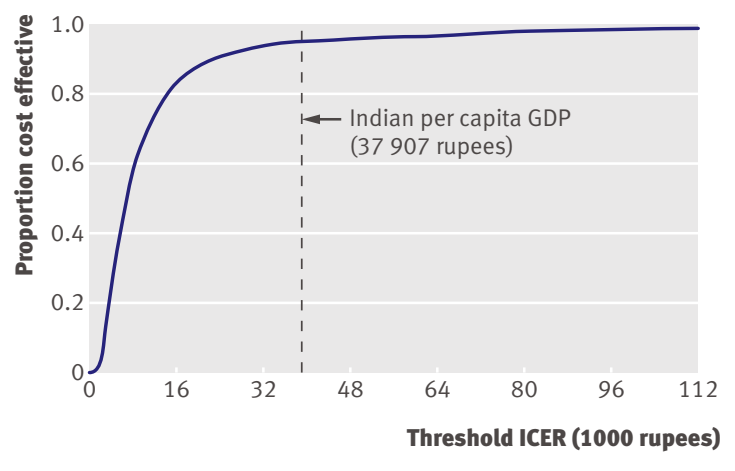

Fig 4 Acceptability curve for strategy of vaccination with live attenuated human rotavirus vaccine (RIX4414) compared with no rotavirus vaccination. Curve represents probability that vaccination would be cost effective over range of threshold incremental cost effectiveness ratios (ICERs) 
admission would probably have been observed, as suggested by the fact that $98 \%$ of admissions in the source study occurred in children younger than 24 months. ${ }^{11}$

Kim et al recently published an analysis of rotavirus vaccination in Vietnam. ${ }^{30}$ Though not individual based, their model shares some key features with ours, including acquired partial immunity from past infections and the possibility of multiple rotavirus infections. The authors also drew several epidemiological parameters from the Velazquez birth cohort study of Mexican infants. ${ }^{2}$ They assumed that deaths related to rotavirus, admissions to hospital, and outpatient visits all decrease in proportion to one another under vaccination. This approach fails to take into account the effects of decreased severity of symptoms on relative rates of use of inpatient and outpatient services. Because we modelled the effects of vaccination on severity of symptoms and the effects of severity on probabilities of service use in specific settings, we could simulate the shift toward lower levels of care needed for children with rotavirus disease under vaccination (that is, larger decreases in admissions than in outpatient visits).

With their model Kim et al examined vaccination in a setting with a rate of rotavirus mortality substantially lower than that seen in India. ${ }^{30}$ This limits the applicability of their findings for countries that, like India, have the highest rates of rotavirus mortality. ${ }^{1422}$ Parameters specific to these other high mortality countries (vaccine coverage rates, rates of service use, costs, etc) would differ from those in India. The consistency of our model's conclusions over wide ranges of parameter inputs in sensitivity analysis suggests that vaccination would probably offer enormous public health benefit in many of these settings.

Irrespective of cost effectiveness, a public health intervention must also be affordable. Net of savings from reduced expenditures on subsidised treatment, we calculated that universal RIX4414 vaccination would cost the Indian Department of Health and Family Welfare $11.6 \mathrm{bn}$ rupees (about $£ 140 \mathrm{~m}, € 160 \mathrm{~m}$, $\$ 240 \mathrm{~m}$ ) annually or, for context, about $11.6 \%$ of that department's 2006-7 budget. ${ }^{65}$ Whether this level of cost is acceptable is a decision to be made by country officials and the international organisations that would help finance mass vaccination. Fortunately, less expensive rotavirus vaccines might be just a few years away if the efforts of some Indian firms and officials in partnership with the National Institutes of Health, the Centers for Disease Control and Prevention, and the Program for Appropriate Technology in Health are successful. These agencies are supporting the development of candidate rotavirus vaccines based on native strains to be manufactured and used in some developing Asian countries, including India. ${ }^{192425}$ Currently, the diphtheria-tetanus-pertussis and hepatitis B vaccines used in India are produced domestically for less than $\$ 1$ a dose. ${ }^{66}$ Officials with a company hoping to manufacture India's first homegrown rotavirus vaccine have likewise set a goal of producing the agent for $\$ 1$ a dose ${ }^{67}$ According to our model, a universal rotavirus vaccination programme with a per dose cost equivalent to $\$ 1$ would cost 1644 rupees $(£ 20, € 23, \$ 34)$ per life year saved, with a total annual cost equal to about 2.2\% of the 2006-7 Indian Department of Health and Family Welfare's budget. This figure does not take into account possible benefits of improved efficacy provided by a vaccine derived from native strains.

We compared universal rotavirus vaccination to the status quo of no rotavirus vaccination. Future analyses should compare the cost effectiveness of rotavirus vaccination with possible strategies using other less expensive but underused interventions to reduce child mortality. One such intervention might be expansion of micronutrient supplementation and fortification programmes. In India, deficiencies of micronutrients are reportedly associated with more deaths than rotavirus, with around 330000 child deaths each year attributed to vitamin A deficiency alone. ${ }^{68}$ Despite this, supplementation and fortification programmes remain inadequate. ${ }^{6869}$

\section{Limitations}

Whenever possible, we based parameter estimates on data specific for India. Incidence and severity (but not service use or mortality) parameters in our model, however, were based on the results of a Mexican birth cohort study. ${ }^{2}$ Evidence suggests that incidence rates of rotavirus infection are similar worldwide and across economic strata ${ }^{1-7}$ and that survival is largely a function of access to medical care. ${ }^{1138}$ It is reasonable to expect though that average symptom severity might be greater in poorer countries, where underlying health tends to be worse, compared with severity in an upper middle income ${ }^{70}$ country like Mexico. In sensitivity analysis, we showed that any potential underestimation of disease burden would bias the analysis against the intervention. Vaccination would become twice as cost effective if infection rates, probability that infections were symptomatic, and probability that any symptoms were severe were all simultaneously increased by 50\%. Less apparent is the direction of any mis-specification of severity dependent probabilities of service use. Because these types of data were not directly available in the published literature, we were forced to make inferences based partly on data specific to India ${ }^{38}$ and partly on previous estimates of rotavirus related use of health services in inpatient and outpatient settings for developing countries in general. ${ }^{8}$ In particular, the model's conclusions were sensitive to variation in the probability that those with severe rotavirus disease would receive outpatient care. In the extreme, increasing this probability by $50 \%$ (from 0.575 to 0.863 ) would result in an incremental cost effectiveness ratio equivalent to about 1.4 times India's per capita gross domestic product, falling between the WHO's criteria for "very cost effective" (one times per capita gross domestic product) and "cost effective" (three times per capita gross domestic product) interventions. ${ }^{55}$

Earlier live oral vaccines against rotavirus, ${ }^{71-74}$ as well as those against cholera ${ }^{75-77}$ and polio, ${ }^{7879}$ have 


\section{WHAT IS ALREADY KNOWN ON THIS TOPIC}

Nearly a quarter of deaths from rotavirus gastroenteritis occur in India, a country with a high degree of rotavirus strain diversity, limited access to health care, and tightly constrained financial resources.

WHO has recently recommended rotavirus vaccination in developing countries of Asia and Africa

\section{WHAT THIS STUDY ADDS}

A model based on India specific inputs where possible, showed a $29.7 \%$ reduction in

symptomatic episodes, $41.0 \%$ reduction in rotavirus mortality, $33.3 \%$ reduction in outpatient visits, and $34.3 \%$ reduction in hospital admissions with a programme of vaccination with RIX4414

A vaccination programme would satisfy standard criteria for cost effectiveness across a wide range of assumptions-including lower than expected vaccine efficacy-albeit at a substantial net programme cost
RLH, and BW performed the literature review. JR performed the analyses with advice from MES. JR wrote the text of the manuscript with input from $\mathrm{RLH}, \mathrm{BW}$, and MES. All authors reviewed and approved the final version of the paper. JR is guarantor.

Funding: JR and RLH received support from a US Department of Health and Human Services Agency for Healthcare Research and Quality institutional training grant. No other direct funding was received for this study.

Role of funder: AHRQ played no role in the design or conduct of the study, or in the decision to submit for publication.

Competing interests: None declared.

Ethical approval: Not required.

1 De Zoysa I, Feachem RG. Interventions for the control of diarrhoeal diseases among young children: rotavirus and cholera immunization. Bull World Health Organ 1985;63:569-83.

2 Velazquez FR, Matson DO, Calva JJ, Guerrero L, Morrow AL, Carter-Campbell S, et al. Rotavirus infections in infants as protection against subsequent infections. N Engl J Med 1996;335:1022-8.

3 Linhares AC, Gabbay YB, Freitas RB, da Rosa ES, Mascarenhas JD, Loureiro EC. Longitudinal study of rotavirus infections among children from Belem, Brazil. Epidemiol Infect 1989;102:129-45.

4 Rodriguez WJ, Kim HW, Brandt CD, Schwartz RH, Gardner MK, Jeffries B, et al. Longitudinal study of rotavirus infection and gastroenteritis in families served by a pediatric medical practice: clinical and epidemiologic observations. Pediatr Infect Dis J 1987;6:170-6.

5 Simhon A, Mata L, Vives M, Rivera L, Vargas S, Ramirez G, et al. Low endemicity and low pathogenicity of rotaviruses among rural children in Costa Rica. J Infect Dis 1985;152:1134-42.

6 Black RE, Lopez de Romana G, Brown KH, Bravo N, Bazalar OG, Kanashiro HC. Incidence and etiology of infantile diarrhea and major routes of transmission in Huascar, Peru. Am J Epidemiol 1989;129:785-99.

7 Zaki AM, DuPont HL, el Alamy MA, Arafat RR, Amin K, Awad MM, et al The detection of enteropathogens in acute diarrhea in a family cohor population in rural Egypt. Am J Trop Med Hyg 1986;35:1013-22.

8 Parashar UD, Hummelman EG, Bresee JS, Miller MA, Glass RI. Global illness and deaths caused by rotavirus disease in children. Emerg Infect Dis 2003;9:565-72.

9 Mrukowicz J, Szajewska H, Vesikari T. Options for the prevention of rotavirus disease other than vaccination. J Pediatr Gastroenterol Nutr 2008;46(suppl 2):S32-7.

10 WHO. Estimated rotavirus deaths for children under 5 years of age: 2004. Geneva: WHO,

2009. www.who.int/immunization_monitoring/burden/ rotavirus_estimates/en/index.html.

11 Bahl R, Ray P, Subodh S, Shambharkar P, Saxena M, Parashar U, et al. Incidence of severe rotavirus diarrhea in New Delhi, India, and and $\mathrm{P}$ types of the infecting rotavirus strains. J Infect Dis 2005;192(suppl 1):S114-9.

12 Diarrhoea treatment guidelines including new recommendations for the use of ORS and zinc supplementation for clinic-based healthcare workers. Washington: USAID Micronutrient Program, 2005. http://whqlibdoc.who.int/publications/2005/a85500.pdf.

13 Dennehy PH. Rotavirus vaccines-an update. Vaccine 2007;25:3137-41.

14 Glass RI, Bresee JS, Turcios R, Fischer TK, Parashar UD, Steele AD. Rotavirus vaccines: targeting the developing world. J Infect Dis 2005;192(suppl 1):S160-6.

15 Vesikari T, Matson DO, Dennehy P, Van Damme P, Santosham M, Rodriguez Z, et al. Safety and efficacy of a pentavalent human-bovine (WC3) reassortant rotavirus vaccine. N Engl J Med 2006;354:23-33.

16 Ruiz-Palacios GM, Perez-Schael I, Velazquez FR, Abate H, Breuer T, Clemens SC, et al. Safety and efficacy of an attenuated vaccine against severe rotavirus gastroenteritis. $N$ Engl J Med 2006;354:11-22.

17 Angel J, Franco MA, Greenberg HB. Rotavirus vaccines: recent developments and future considerations. Nat Rev Microbiol 2007; 5:529-39.

18 Vesikari T, Karvonen A, Prymula R, Schuster V, Tejedor JC, Cohen R, et al. Efficacy of human rotavirus vaccine against rotavirus gastroenteritis during the first 2 years of life in European infants: randomised, double-blind controlled study. Lancet 2007;370:1757-63.

19 Glass R, Parashar U, Bresee J, Turcios R, Fischer T, Widdowson M, et al. Rotavirus vaccines: current prospects and future challenges. Lancet 2006;368:323-32.

20 Santos N, Hoshino Y. Global distribution of rotavirus serotypes/ genotypes and its implication for the development and implementation of an effective rotavirus vaccine. Rev Med Virol 2005;15:29-56. and fortification programmes to make certain that the most cost effective solutions do not go unexploited.

Contributors: JR conceived the original idea for the study. JR, RLH, BW, and MES developed the idea and contributed to the design of the study. JR, 
21 Gentsch JR, Laird AR, Bielfelt B, Griffin DD, Banyai K, Ramachandran M, et al. Serotype diversity and reassortment between human and animal rotavirus strains: implications for rotavirus vaccine programs. J Infect Dis 2005;192(suppl 1):S146-59.

22 Naghipour M, Nakagomi T, Nakagomi O. Issues with reducing the rotavirus-associated mortality by vaccination in developing countries. Vaccine 2008;26:3236-41.

23 WHO. Rotavirus vaccination. Wkly Epidemiol Rec 2009;84:213-36

24 Parashar UD, Glass RI. Public health. Progress toward rotavirus vaccines. Science 2006;312:851-2.

25 PATH. Proceedings of the 7th international symposium on rotavirus and rotavirus vaccines June 12-13. 2006. Lisbon, Portugal: Albert $B$ Sabin Vaccine Institute,

2006. www.path.org/vaccineresources/files/ Rotavirus symposium proceedings Lisbon2006.pdf.

26 WHO. Rotavirus vaccines. Wkly Epidemiol Rec 2007;82:285-95.

27 Fischer TK, Anh DD, Antil L, Cat ND, Kilgore PE, Thiem VD, et al. Health care costs of diarrheal disease and estimates of the costeffectiveness of rotavirus vaccination in Vietnam. J Infect Dis 2005;192:1720-6.

28 Podewils LJ, Antil L, Hummelman E, Bresee J, Parashar UD, Rheingans R. Projected cost-effectiveness of rotavirus vaccination for children in Asia. J Infect Dis 2005;192(suppl 1):S133-45.

29 Isakbaeva ET, Musabaev E, Antil L, Rheingans R, Juraev R, Glass RI, et al. Rotavirus disease in Uzbekistan: cost-effectiveness of a new vaccine. Vaccine 2007;25:373-80.

30 Kim SY, Goldie SJ, Salomon JA. Cost-effectiveness of rotavirus vaccination in Vietnam. BMC Public Health 2009;9:29.

31 WHO. Immunization profile -India. Geneva: WHO, 2008. www.who.int/immunization_monitoring/en/globalsummary/ countryprofileresult.cfm.

32 Steele AD, De Vos B, Tumbo J, Reynders J, Scholtz F, Bos P, et al. Coadministration study in South African infants of a live-attenuated ora human rotavirus vaccine (RIX4414) and poliovirus vaccines. Vaccine 2008 Sep 8.

33 Zaman K, Sack DA, Yunus M, Arifeen SE, Podder G, Azim T, et al. Successful co-administration of a human rotavirus and oral poliovirus vaccines in Bangladeshi infants in a 2-dose schedule at 12 and 16 weeks of age. Vaccine 2009;27:1333-9.

34 Ruuska T, Vesikari T. Rotavirus disease in Finnish children: use of numerical scores for clinical severity of diarrhoeal episodes. Scand Infect Dis 1990;22:259-67.

35 Cortese MM, Parashar UD. Prevention of rotavirus gastroenteritis among infants and children: recommendations of the advisory committee on immunization practices (ACIP). MMWR Recomm Rep 2009;58:1-25.

36 Dennehy PH. Rotavirus vaccines: an overview. Clin Microbiol Rev 2008;21:198-208.

37 Fischer TK, Valentiner-Branth P, Steinsland H, Perch M, Santos G, Aaby $P$, et al. Protective immunity after natural rotavirus infection: a community cohort study of newborn children in Guinea-Bissau, West Africa. J Infect Dis 2002;186:593-7.

38 Banerjee I, Ramani S, Primrose B, Moses P, Iturriza-Gomara M, Gray JJ, et al. Comparative study of the epidemiology of rotavirus in children from a community-based birth cohort and a hospital in South India. I Clin Microbiol 2006;44:2468-74.

39 WHO. Life tables for WHO member states. Geneva: WHO, 2006. http://apps.who.int/whosis/database/life_tables/ life tables.cfm

40 Rose J, Singer ME. Projecting vaccine efficacy: accounting for geographic strain variations. Pharmacoeconomics 2008;26:185-9.

41 De Vos B, Han HH, Bouckenooghe A, Debrus S, Gillard P, Ward R, et al. Live attenuated human rotavirus vaccine, RIX4414, provides clinical protection in infants against rotavirus strains with and without shared G and P genotypes. Ped Infect Dis / 2009;28:261-6.

42 Sharma S, Ray P, Gentsch JR, Glass RI, Kalra V, Bhan MK. Emergence of $\mathrm{G} 12$ rotavirus strains in Delhi, India, in 2000 to 2007. J Clin Microbiol 2008;46:1343-8.

43 Samajdar S, Ghosh S, Chawla-Sarkar M, Mitra U, Dutta P, Kobayashi N, et al. Increase in prevalence of human group A rotavirus G9 strains as an important VP7 genotype among children in eastern India. J Clin Virol 2008;43:334-9.

44 Lopez P, Linhares A, Perez-Schael I, Ruiz-Palacios G, Costa Clemens S, Sanchez N, et al. Early protection against severe rotavirus gastroenteritis-RIX4414 experience in Latin America. In: 24th Annual Meeting of the European Society of Infectious Diseases; 2006 May 3-5. Basel, Switzerland: 2006.

45 Linhares AC, Velazquez FR, Perez-Schael I, Saez-Llorens X, Abate H, Espinoza $F$, et al. Efficacy and safety of an oral live attenuated human rotavirus vaccine against rotavirus gastroenteritis during the first 2 years of life in Latin American infants: a randomised, double-blind, placebo-controlled phase III study. Lancet 2008;371:1181-9.

46 Global Advisory Committee on Vaccine Safety, 17-18 December 2008. Wkly Epidemiol Rec 2009;84:37-40.
47 Mendelsohn AS, Asirvatham JR, Mkaya Mwamburi D, Sowmynarayanan TV, Malik V, Muliyil J, et al. Estimates of the economic burden of rotavirus-associated and all-cause diarrhoea in Vellore, India. Trop Med Int Health 2008;13:934-42.

48 Jain V, Parashar UD, Glass RI, Bhan MK. Epidemiology of rotavirus in India. Indian J Pediatr 2001;68:855-62.

49 Rheingans RD, Constenla D, Antil L, Innis BL, Breuer T. Potential costeffectiveness of vaccination for rotavirus gastroenteritis in eight Latin American and Caribbean countries. Rev Panam Salud Publica 2007;21:205-16.

50 WHO. Guidelines for estimating the economic burden of diarrhoeal disease with focus on assessing the costs of rotavirus diarrhoea. Geneva: WHO,

2005. www.who.int/vaccine_research/documents/ Eco Burden Diarrhoeal.pdf.

51 Valencia-Mendoza A, Bertozzi SM, Gutierrez JP, Itzler R. Costeffectiveness of introducing a rotavirus vaccine in developing countries: the case of Mexico. BMC Infect Dis 2008;8:103.

52 WHO. National burden of disease studies: a practical guide. Geneva: WHO,

2001. www.who.int/healthinfo/nationalburdenofdiseasemanual. pdf.

53 Murray C, Lopez A, eds. The global burden of disease: a comprehensive assessment of mortality and disability from diseases, injuries and risk factors in 1990 and projected to 2020. Cambridge: Harvard School of Public Health on behalf of the World Health Organization and the World Bank, 1996.

54 Lahiri S, Levenstein C, Nelson DI, Rosenberg BJ. The cost effectiveness of occupational health interventions: prevention of silicosis. Am J Ind Med 2005;48:503-14.

55 WHO. The world health report 2002-reducing risks, promoting healthy lives. Geneva: WHO, 2002. www.who.int/whr/2002/en/.

56 Briggs $\mathrm{AH}$. Handling uncertainty in cost-effectiveness models. Pharmacoeconomics 2000;17:479-500.

57 Del Rio RA, Post AB, Singer ME. Cost-effectiveness of hematologic growth factors for anemia occurring during hepatitis $\mathrm{C}$ combination therapy. Hepatology 2006;44:1598-606.

58 Sisk JE, Whang W, Butler JC, Sneller VP, Whitney CG. Costeffectiveness of vaccination against invasive pneumococcal disease among people 50 through 64 years of age: role of comorbid conditions and race. Ann Intern Med 2003;138:960-8.

59 De Wals P, Nguyen VH, Erickson LJ, Guay M, Drapeau J, St-Laurent J. Cost-effectiveness of immunization strategies for the control of serogroup C meningococcal disease. Vaccine 2004:22:1233-40.

60 Dayan GH, Nguyen VH, Debbag R, Gomez R, Wood SC. Costeffectiveness of influenza vaccination in high-risk children in Argentina. Vaccine 2001;19:4204-13.

61 Thiry N, De Laet C, Hulstaert F, Neyt M, Huybrechts M, Cleemput I. Cost-effectiveness of human papillomavirus vaccination in Belgium do not forget about cervical cancer screening. Int J Technol Assess Health Care 2009;25:161-70.

62 Zahn M, Marshall GS. Clinical and epidemiological aspects of rotavirus infection. Pediatr Ann 2006;35:23-8.

$63 \mathrm{CIA}$. The world factbook. Central Intelligence Agency, 2008. www.cia.gov/library/publications/the-world-factbook/index. html.

64 Public Information Bureau. Advance estimates of national income 2007-08. Government of India, February 7, 2008 (press release).

65 Indian National Information Centre. Union Budget 2007-2008. 2007. http://indiabudget.nic.in/ub2007-08/bag/bag4-2.pdf.

66 Madhavi Y. New combination vaccines: backdoor entry into India's universal immunization programme. Current Science 2006;90:1465-9.

67 Jaffe S. New rotavirus vaccines on the horizon. Scientist 2005;19:37.

68 Kotecha P. Micronutrient malnutrition in India: let us say no to it now. Indian I Community Med 2008;33:9-10.

69 India micronutrient national investment plan for 2007-2011 launched today. New Delhi: India PRWire, 2006. www.indiaprwire.com/pressrelease/health-care/ 20061019819.htm.

70 World Bank country classification table. Washington: World Bank, 2008. http://web.worldbank.org/WBSITE/EXTERNAL/ DATASTATISTICS/0, contentMDK:20421402 pagePK:64133150 piPK:64133175 theSitePK:239419,00.html

71 Georges-Courbot MC, Monges J, Siopathis MR, Roungou JB, Gresenguet G, Bellec L, et al. Evaluation of the efficacy of a low passage bovine rotavirus (strain WC3) vaccine in children in Central Africa. Res Virol 1991;142:405-11.

72 Hanlon P, Hanlon L, Marsh V, Byass P, Shenton F, Hassan-King M, et al. Trial of an attenuated bovine rotavirus vaccine (RIT 4237) in Gambian infants. Lancet 1987;1:1342-5.

73 Lanata CF, Black RE, del Aguila R, Gil A, Verastegui H, Gerna G, et al. Protection of Peruvian children against rotavirus diarrhea of specific 
serotypes by one, two, or three doses of the RIT 4237 attenuated bovine rotavirus vaccine. I Infect Dis 1989;159:452-9.

74 Clark HF, Offit PA, Ellis RW, Eiden JJ, Krah D, Shaw AR, et al. The development of multivalent bovine rotavirus (strain WC3) reassortant vaccine for infants. I Infect Dis

1996;174(suppl 1):S73-80.

75 Qadri F, Chowdhury MI, Faruque SM, Salam MA, Ahmed T, Begum YA, et al. Peru-15, a live attenuated oral cholera vaccine, is safe and immunogenic in Bangladeshi toddlers and infants. Vaccine 2007;25:231-8.

76 Clemens JD, Stanton BF, Chakraborty J, Sack DA, Khan MR, Huda S, et al. B subunit-whole cell and whole cell-only oral vaccines against cholera: studies on reactogenicity and immunogenicity. J Infect Dis 1987;155:79-85.
77 Richie EE, Punjabi NH, Sidharta YY, Peetosutan KK, Sukandar MM, Wasserman SS, et al. Efficacy trial of single-dose live oral cholera vaccine CVD 103-HgR in North Jakarta, Indonesia, a cholera-endemic area. Vaccine 2000;18:2399-410.

78 John TJ. Antibody response of infants in tropics to five doses of oral polio vaccine. BMJ 1976;i:812.

79 Minor PD. Polio eradication, cessation of vaccination and reemergence of disease. Nat Rev Microbiol 2004;2:473-82.

80 Patel AB, Dhande LA, Rawat MS. Economic evaluation of zinc and copper use in treating acute diarrhea in children: a randomized controlled trial. Cost Eff Resour Alloc 2003;1:7.

Accepted: 4 June 2009 